\title{
Effect on the energy market of the potential switching to heat pumps for space heating
}

\author{
Sara A. Alla*, Vinecnzo Bianco, Luca A. Tagliafico, Federico Scarpa \\ University of Genoa, DIME-TEC / UNIGE, via All'Opera Pia 15/A, Genoa 16154, Italy
}

Corresponding Author Email: sara.abd.alla@edu.unige.it

$\underline{\text { https://doi.org/10.18280/mmc_c.790312 }}$

Received: 2 May 2018

Accepted: 10 June 2018

\section{Keywords:}

power market, fuel switching, heat pump heating, residential buildings

\begin{abstract}
The main subject of this work is to understand what could happen in the Italian electricity market if a given share of building heating demand had switched from gas to electricity heating devices. The objective is to define the optimal share to switch in terms of minimization of environmental $\left(\mathrm{CO}_{2}\right)$ emissions. The effects of such switching on the national energy system are analyzed from the financial point of view, depending also on the heating habits of final users.

An hourly simulation of the electricity market has been performed by means of a bid stack model (BIDSM) developed at University of Genoa, calculating market prices, power plant generation typology, fuel consumption and global $\mathrm{CO}_{2}$ emissions.

All the data are averaged on a national basis and results are reported for two different time schedule of heating requirements of the final users. In each case, the total energy consumption is fixed, and local "degree days" and location energy needs are considered. It seems that the use of heat pumps for building heating is a real option and that the user habits has a little impact on optimal share of switching from gas to heat pumps, at least concerning $\mathrm{CO}_{2}$ emission minimization.
\end{abstract}

\section{INTRODUCTION}

Space heating is one of the main causes of energy consumption and pollution in residential buildings. European data available in [1], highlight the need for new solutions in order to decrease the carbon emissions and the primary energy demand. This problem is particularly important in Italy, where primary energy supply relies strongly on import and this can affect the national security of supply. Indeed, political stability of the suppliers can strongly affect reliability of provisions and stable access to natural gas and other fuels [2]. In this framework [3-4], any improvement or technique able to increase renewable energy share [5] and diversify the primary energy mix would help to reduce the supply risk and to decrease emissions.

The massive deployment of renewable energy plants is one of the most commonly proposed measures to reach the goal of reducing primary energy consumption [6-7]. Other important fields are related to co-generation, energy performance improvement of buildings and energy labeling.

The building sector, followed by transport [8], is the most energy demanding in the end-user's area and accounts for $40 \%$ of the total energy consumption [8-10].

Therefore, a lot of efforts and researches are devoted to building heating in order to understand the economic and the power market impact of several measures, stepping from the market forecasting [11] to potential befits resulting from building envelope insulation [12].

Heating plants improvements, and in particular the widespread use of heat pumps, have been analyzed in many countries such as Denmark [13], Lithuania [14], UK [15] and France [16]. Indeed, the above-mentioned papers involve industrial solutions with a lot of examples of heat recovery where heat pump applications are relevant. In Italy, Caldera et alii proposed a survey-based analysis of the electrical energy demand in Italian households where the numerical model allows allocating the electrical energy consumption for each end-use, in order to obtain a reliable estimation of the households' habits in the residential sector and propose efficiency scenarios [17].

The present paper studies the impact of the spread of heat pumps for residential heating in Italy, leading to the switching of energy supply for heating purposes from gas to electricity market. As a consequence, new values of power price, primary energy consumption and carbon emission result and are compared to the actual situation in year 2015. Year 2015 is the most recent year with available stable and complete energy consumption data [18].

This approach is based on the idea that the local environmental and working conditions in Italy should be particularly favorable for heat pump utilization, so that high coefficient of performance in terms of "electricity to heat" conversion could guarantee a global saving of primary energy.

The main objective of the present paper is to understand if there is an optimal share to switch, in terms of minimization of primary energy consumption and environmental $\left(\mathrm{CO}_{2}\right)$ emissions, for a given technological level of actually available commercial heat pumps, for given climates and final user habits. Finally, it is stated to what extent such switching is convenient for the national energy system from the financial point of view.

\section{MODEL IMPLEMENTATION}

The proposed methodology estimates the possible primary energy savings obtained by shifting the buildings' heating consumption from the natural gas market to the electricity one, evaluating the corresponding increase of electricity 
consumption and its impact on the electricity generation mix, that changes according to the corresponding increased electricity demand.

To this aim, the following steps were completed:

- estimation of the hourly heating energy requirements based on global gas consumption data;

- calculation of the hourly and average COP of the HP based on the climate temperature profiles of three representative locations (Milan, Rome, Naples), the heating profiles (two different daily distribution of heating schedule) and the performance of common commercially available HPs;

- analysis of the increase of the demand for electricity and its impact on the national energy mix in terms of market prices and $\mathrm{CO}_{2}$ emissions;

- optimization of the switching rate from gas to electricity heating, based on a global emissions minimization target.

\subsection{The natural gas supply for residential space heating and building heating demand}

Nowadays, Italy heating demand mainly relies on natural gas. Indeed, the gas consumption in Italy is mainly due to space heating $(63 \%)$, less to thermoelectric power conversion $(25 \%)$ and about $12 \%$ for industrial uses [19]. Even if detailed daily consumptions are available from gas databases [20], the present analysis estimates the share specifically dedicated to residential heating. Following the procedure pursued in [22] the base load $\mathrm{E}_{\mathrm{b}}$ constant all over the year (devoted to domestic hot water (DHW) and cooking purposes) can be guessed. For the year $2015 \mathrm{E}_{\mathrm{b}}$ was about $440 \mathrm{GWh} /$ day.

The daily net amount of natural gas required for winter heating $E_{h}$ is calculated for each month of the year as follows:

$\mathrm{E}_{\mathrm{h}}=\mathrm{E}-\mathrm{E}_{\mathrm{b}}$

where $\mathrm{E}$ is the daily gross energy consumption of natural gas. The energy determined by means of Eq. (1) has been obtained on the basis of historical (years 2012-2017) data and represents an actual value.

On the other hand, in order to determine the load due to buildings heating, it is necessary to estimate the hourly consumption of natural gas. To this purpose the heating degree days national hourly values $\left(\mathrm{HDD}_{\mathrm{h}}\right)$ were defined as a weighted average on the hourly values of three main Italian cities: Naples, Rome and Milan. $\mathrm{HDD}_{\mathrm{h}}$ values were calculated through historical temperature measurement data published by Eurometeo [21].

It is assumed that a temperature of $20^{\circ} \mathrm{C}$ is kept as internal temperature of the buildings, therefore the hourly degree day for the hour " $h$ " is defined as:

$\mathrm{HDD}_{\mathrm{h}}=20-\mathrm{T}_{\mathrm{ext}, \mathrm{h}}$

where $T_{\text {ext,h }}$ is the external environmental temperature for the hour " $h$ ".

Considering the $21^{\text {st }}$ day of every month as a meaningful representative for the thermo-behavior of the whole month, average hourly temperatures are calculated for the year 2015 . In the present study, it is assumed to include the months of November, December, January, February, March, and April, namely the most common heating season in Italy.

The daily degree day are calculated by summing the hourly degree day during the whole day, namely:
$H D D_{D}=\sum_{h=1}^{24} H D D_{h}$

In order to estimate the hourly natural gas consumption for heating purposes, the following weighting factor is calculated for each hour:

$\alpha_{i}=\frac{H D D_{h}}{H D D_{D}}$

By multiplying $\alpha_{i}$ for $E_{h}$, the hourly heating natural gas consumption is estimated.

The net thermal energy needs to heat the building, $\mathrm{Q}_{\mathrm{h}}$, are obtained from gas combustion by means of standard gas burners with average combustion efficiency $\eta_{\mathrm{b}}$ on the basis of gas Low Heating Value ( $\mathrm{LHV}, \mathrm{H}_{\mathrm{L}}$ ). This efficiency is here assumed equal to $80 \%$, as suggested in [11]. On the other hand, the $E_{h}$ values are given in energy units $(G W h)$ with reference to natural gas High Heating Value $\left(\mathrm{HHV}, \mathrm{H}_{\mathrm{H}}\right)$. Therefore, actual $\mathrm{Q}_{\mathrm{h}}$ needs are calculated as follows:

$Q_{h}=E_{h} \frac{H_{L}}{H_{H}} \eta_{b}$

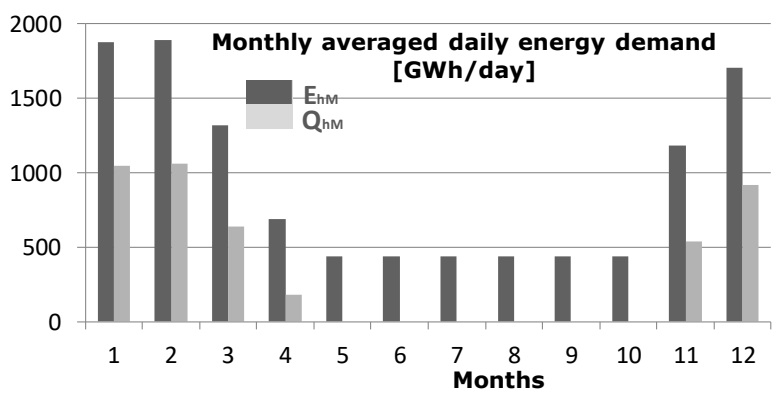

Figure 1. Monthly gas energy consumption in Italy. Total value (black) $\mathrm{E}_{\mathrm{hM}}(\mathrm{GWh} /$ month) referred to the gas Higher

Heating Value $\left(\mathrm{H}_{\mathrm{H}}\right)$ and the corresponding residential monthly heating needs (grey) $\mathrm{Q}_{\mathrm{hM}}\left(\mathrm{GWh} /\right.$ month). $\mathrm{Q}_{\mathrm{hM}}$ is calculated assuming averaged national gas burner efficiency $\eta_{b}=0.8$, referred to Lower gas Heating value $\left(\mathrm{H}_{\mathrm{L}}\right) . \mathrm{H}_{\mathrm{H}} / \mathrm{H}_{\mathrm{L}}=1.1$. Non-heated months show the base load $\mathrm{E}_{\mathrm{b}}=440$ $\mathrm{GWh} /$ month

\subsection{The hourly COPs and the electricity load to satisfy building heating demand}

Italian regulation allows a maximum number of hours per day devoted to heating, depending on the national climate zones. Since the total daily heating amount is fixed as described above, hourly peak values of the gas consumption can change depending on the user demand profiles. In line with this, this paper proposes two user demand profiles of a maximum 10 hours heating, in order two analyze the different HPs electrical consumption and the corresponding impact on the power market. Both profiles could be assumed to be representative of the behavior of two different classes of Italian population.

The hourly electricity consumption $\mathrm{L}_{h}$ is a function of the average HP's $\mathrm{COP}_{h}$

$L_{h}=\frac{Q_{h}}{C O P_{h}}$ 
The national $\mathrm{COP}_{\mathrm{h}}$ value is calculated as an average of the three main Italian cities: Naples, Rome and Milan. The main idea is to use cheap and easy to maintain air-to-air heat pumps, the simplest and most common technology in refrigeration industry for Italy.

In light of available technologies performance, the actual COP of the devices is correlated to actual working temperatures, $\mathrm{T}_{\text {ext }}$ and $\mathrm{T}_{\mathrm{amb}}$, and to the specific efficiency of each component of the heat pump. In particular heat exchanger performance (evaporator and condenser) are quantified in terms of heattransfer temperature gradients $(\Delta \mathrm{T})$, while expansion valves and compressors are qualified as a whole in terms of "second law" efficiency $\eta_{\mathrm{ex}}$. The hourly $\mathrm{COP}_{\mathrm{h}}$ can be therefore calculated in the form:

$$
C O P_{h}=\frac{T_{e x t}+\Delta T_{e v}}{\left(T_{a m b}+\Delta T_{c o n d}\right)-\left(T_{e x t}+\Delta T_{e v}\right)} \eta_{e x}
$$

In this paper the following reference values were assumed:

$$
\begin{aligned}
& \Delta T_{e v}=-10\left[{ }^{\circ} \mathrm{C}\right] \\
& \Delta T_{\text {cond }}=15\left[{ }^{\circ} \mathrm{C}\right] \\
& \eta_{e x}=0,4
\end{aligned}
$$

The value of COP is the mean of actual $\mathrm{COP}_{h}$ values all over the HP's operating time. For this reason a different choice in heating time schedule give rise to different hours of the day in which the HP is on, with different external working temperatures and corresponding relevant differences in COP actual values. To be noticed that the number of operating hours of the HP directly influences the peak values of power demand, as a lower number of hours give rise, for given total thermal energy supply, to higher $L_{h}$ peaks, thus increasing the risk of overloads in the national power grid.

\subsection{Power market model, share of switching and impact on the electricity market}

The preceding paragraphs explain how, to estimate the market impact of the diffusion of heat pumps. A set of available data are considered: natural gas daily consumption, average winter temperature in three different areas of the country and the final user electricity demand.

To analyze how the $\mathrm{L}_{\mathrm{h}}$ extra consumption is covered by the electricity national grid, a bid stack model (BISM), developed at University of Genoa, is used to perform an hourly simulation of the electricity market, determining market price, plants generation and fuel consumption. BISM has already been validated for 2015 [17], so $L_{h}$ values are added to real historical values of electricity hourly consumption EL:

$\mathrm{EL}_{\mathrm{n}}=\mathrm{EL}+\mathrm{L}_{\mathrm{h}}$

where $\mathrm{EL}_{\mathrm{n}}$ is the new value of electricity demand per hour.

The objective of the study is to find the optimal switching rate from natural gas to electricity market, in order to minimize the carbon emissions. At the same time, the energy balance on the power market is to be preserved, avoiding the presence of "unserved energy". In other words, any overload of the power grid must be avoided. To this aim, the following objective function is considered:

$\min \left\{\mathrm{E}_{\mathrm{CO} 2, \mathrm{Tot}}=\mathrm{E}_{\mathrm{CO} 2, \mathrm{G}}+\mathrm{E}_{\mathrm{CO} 2, \mathrm{PM}}\right\}$ subject to:
$0 \leq \mathrm{SR} \leq 1$

\section{$\mathrm{UE}=0$}

where, $\mathrm{E}_{\mathrm{CO} 2, \mathrm{Tot}}$ represents the total carbon emissions, $\mathrm{E}_{\mathrm{CO} 2, \mathrm{G}}$ is the carbon emission level for heating by means of the traditional natural gas based heating systems and $\mathrm{E}_{\mathrm{CO} 2 \mathrm{PM}}$ denotes the carbon emissions from the power market(after switching), whereas SR is the switching rate of heating systems from natural gas to power market. Finally, UE is the "unserved energy" (i.e. the energy exceeding the generation capability of the power market).

$\mathrm{E}_{\mathrm{CO} \text {,PM }}$ is determined according to the BISM model, which consider the new electricity consumption due to the heat pumps, whereas $\mathrm{E}_{\mathrm{CO} 2, \mathrm{G}}$ is estimated on the basis of the natural gas consumption data.

Increasing the switching rate will decrease the $\mathrm{E}_{\mathrm{CO} 2 \mathrm{G}}$ emission from gas burners, but will increase $\mathrm{E}_{\mathrm{CO} 2, \mathrm{PM}}$, not only because of increased electricity demand, but also because of the change in the "merit order", which determines the new power supply mix. These changes will influence also to some extent the power market price.

\section{RESULTS AND DISCUSSION}

Results are presented in terms of primary energy consumption, carbon emissions and power prices according to the different user scenarios. All the results are referred to the optimal market share of heat pumps for buildings heating, calculated according to Eq. (9).

Year 2015 is considered as the object of the analysis with the aim to develop an ex-post investigation of the heat pump potentials in terms of primary energy savings. Further analysis can be developed in order to investigate the future development of the energy system.

The optimization problem reported in Eq. (9) has been solved and optimal market shares of heating load to switch from natural gas to electricity market are determined.

\subsection{The user heating demand profiles}

Given the Italian regulation constraints, which usually limit to a fixed number of hours of gas burned operation the final user can choose the distribution of these heating hours over the day, depending on his habits and daily activities. For instance, active population going to work does not stay at home during the day, and shall preferably turn on the gas burner only in the evening and in the first hours of the morning. On the contrary retired people could prefer to have some home heating also at noon, to have much more comfortable houses for their living at home during the day.

\section{COP of the HP - daily operation (January)}

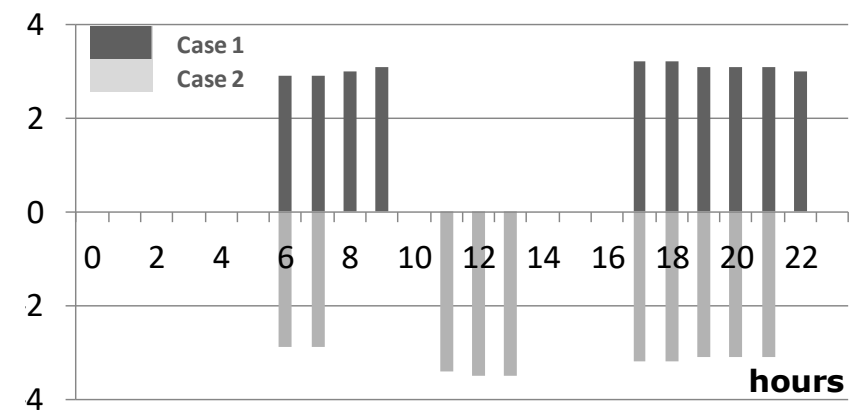




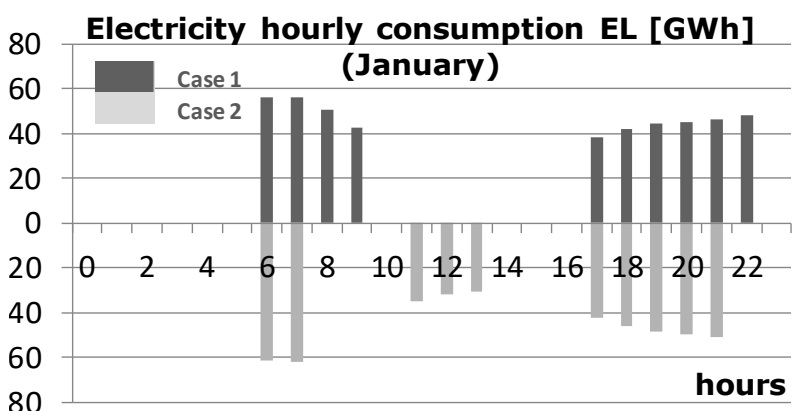

Figure 2. Daily operation of the HP heating system to satisfy final user energy needs. Two different potential scenarios are described in terms of COP value (top) and energy consumption EL (bottom). Void columns mean that the HP is $\mathrm{OFF}$

Since the power grid trends are strongly influenced by the power request during the day, and the COP of the HP depends on environmental working temperatures, final user habits shall have an influence on the final result of primary energy consumption.

In this paper the two above mentioned scenarios have been investigated, keeping the same total amount of heating energy given to the building and the same 10hours of heating system operation.

The two cases are shown in Figure 2 in terms of average HP's COP, calculated for each hour of operation during the day according to Eq. (7) and in terms of corresponding electrical energy demand for the month of January. When there is no column in the figure, this means that the HP is off and the power demand from the grid is zero.

\subsection{Discussion of results}

The main results of the calculation performed are summarized in Table 1, where the yearly data of gas and electricity demand are reported together with global $\mathrm{C}$ emissions, comparing the two scenarios (Case 1 and Case 2) to the situation of NO HP utilization, that is the base case with no intervention on the market of residential heating systems.

Table 1. Results

\begin{tabular}{|c|c|c|c|c|}
\hline & & $\begin{array}{c}\text { NO HP } \\
\text { (only gas } \\
\text { burner) }\end{array}$ & $\begin{array}{c}\text { HP } \\
\text { Case 1 } \\
\text { (HP+gas) }\end{array}$ & $\begin{array}{c}\text { HP } \\
\text { Case } 2 \\
(\text { HP+gas) }\end{array}$ \\
\hline Switch \% & & $0.0 \%$ & $21 \%$ & $18.8 \%$ \\
\hline \multirow[t]{2}{*}{ Gas market } & GAS & 653 & 516 & 530 \\
\hline & $\mathrm{CO}_{2}$ & 35.9 & 28.4 & 29.2 \\
\hline \multirow{2}{*}{$\begin{array}{c}\text { Electricity } \\
\text { market }\end{array}$} & GAS & 1256 & 1335 & 1325 \\
\hline & $\mathrm{CO}_{2}$ & 83.5 & 88 & 87 \\
\hline \multirow[t]{2}{*}{ Total } & GAS & 1909 & 1851 & 1855 \\
\hline & $\mathrm{CO}_{2}$ & 119.4 & 116.4 & 116.6 \\
\hline \multirow{2}{*}{$\begin{array}{l}\text { Global } \\
\text { annual } \\
\text { savings }\end{array}$} & $\begin{array}{l}\text { Prim. } \\
\text { energy }\end{array}$ & 0 & $\begin{array}{c}-58.1 \\
(3.1 \%)\end{array}$ & $\begin{array}{c}-53.7 \\
(2.8 \%)\end{array}$ \\
\hline & $\mathrm{CO}_{2}$ & & -3.02 & -2.82 \\
\hline $\begin{array}{c}\text { Unserved } \\
\text { energy } \\
\text { (ue) }\end{array}$ & & 0 & 0 & 0 \\
\hline
\end{tabular}

Notes: 1. GAS data [PJ] (HHV) - Primary energy [PJ]

$\mathrm{CO}_{2}$ data [Mton]

It is clear that, for the given technological characteristics of the HPs assumed in this paper according to eq. (7), and keeping in mind that the environmental conditions in Italy are as a mean particularly favorable (only in northern Italy, climate in not incline to the use of air-to- air heat pumps).

The table shows that the use of HPs is quite advantageous, with global annual savings of primary energy of the order of $3.1 \%$ in Case 1 and $2.8 \%$ in Case 2, and $\mathrm{CO}_{2}$ emissions reduced of $2.53 \%$ in Case 1 and $2.36 \%$ in Case 2.

This global savings can be translated in a big economical return, considering that the energy value is steadily around $50 € / \mathrm{MWh}$, that is around $14 \mathrm{M} € / \mathrm{PJ}$. The Case 2 is a bit less fruitful than Case 1, due the power demand in the central hours of the day, which are considered particularly critical and expensive from the power generation market. Indeed, Case 1 seems to be more energy demanding in respect of Case 2, but the request is in hour bands where the energy conversion is more efficient, and this result, in final data, in a more global primary energy saving (Figure 3). For the same reason the switching rate result to be a bit higher in Case $1(21 \%)$ in respect of Case $2(18.8 \%)$, because of the higher probability to reach the power limit of the grid

The saving achievements must be compatible with the power potential of the grid (which is guaranteed in the simulations by the constraint $\mathrm{UE}=0$ ) and must be affordable from the market price point of view. Figure 4 reports the energy market price for the three cases, and proves that, even if some influence is evident in the months of September and December, no critical price variation is evidenced.

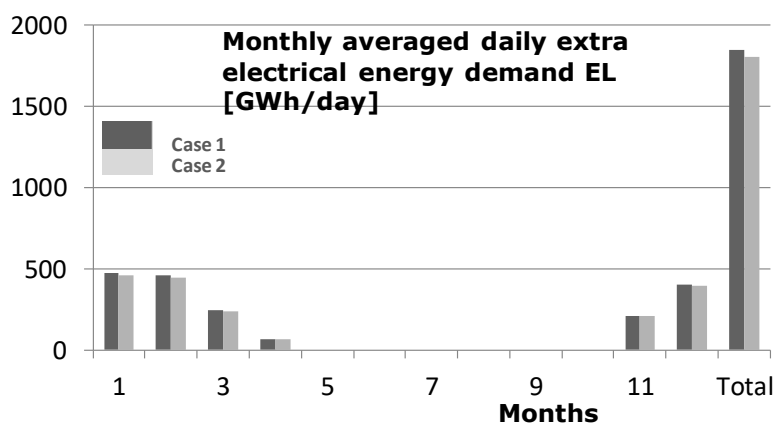

Figure 3. Monthly energy demands EL for Case1 (black) and Case 2 (grey) based on different daily operation. Void columns mean that the HP is OFF. Last column is the annual electricity demand of the HPs

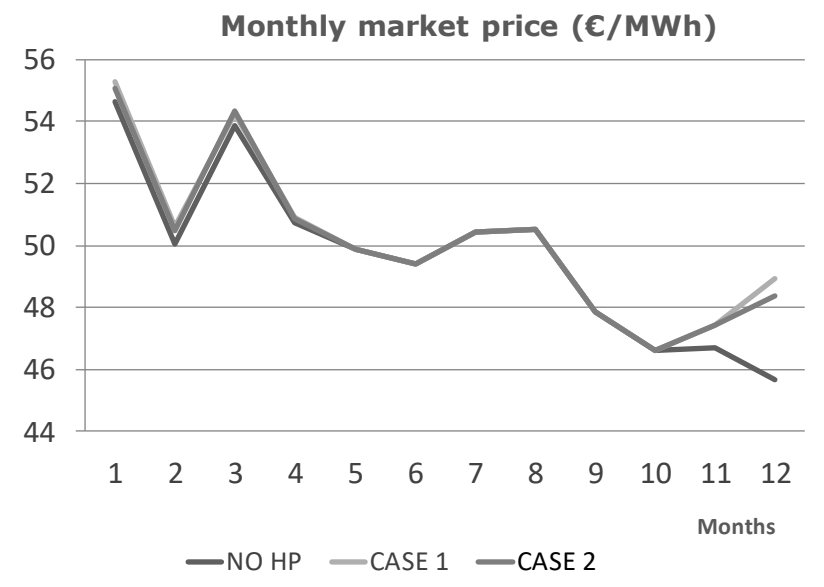

Figure 4. Monthly average energy market price for the three cases here investigated: base (NO HP), HP-Case 1 and HP-Case 2 


\section{CONCLUSIONS}

The main objective of the present paper is to analyze the impact of space heating switching from gas burners to electrical heat pumps in residential buildings. In particular, the optimal share to switch has been calculated to minimize environmental $\left(\mathrm{CO}_{2}\right)$ emissions, within available electrical power, for a given technological level of actually available commercial heat pumps, for given climates (a reasonable mean in Italy) and final user habits. Finally, the impact of such switching on the national energy market price in analyzed.

The main conclusion is that heat pumps area valid alternative to reduce carbon emissions for heating purposes, as well as to save primary energy and to increase the overall efficiency of the Italian energy system.

The user habits influence the results, since even for the same heating energy amount and the same number of heating hours per day, electrical energy demand around noon are more critical for the power grid, with peak limits and lower energy efficiency conversion. Indeed, even if at noon HPs have a higher COP, the used electric power asks for higher primary energy (due to lower conversion efficiency) and therefore the optimal switching is lower (18,8\% in Case 2 compared to $21 \%$ in Case 1).

It is important to highlight that this analysis is preliminary and future work is necessary to analyze significant scenarios for the Italian market. In particular, the present analysis represents an "ex-post" study related to the year 2015, therefore it is necessary to develop future scenarios of development, in order to define long term energy plans and the corresponding energy policies. Furthermore, a total equivalent warming impact (TEWI) analysis of heat pumps might be included. Finally, different countries could have different scenarios and different conclusions, even if the proposed approach and methodology could still be used.

\section{ACKNOWLEDGMENT}

The present work was supported by University of Genoa with the fund "FRA - FONDI PER LA RICERCA DI ATENEO 2015. COD. 100025-2015-VB-FRA_001" and the PRIN 2015 MIUR project "Clean Heating and Cooling Technologies for An Energy Efficient Smart Grid" (UNIGE subproject 100025-2016-LT-PRIN2015_001).

\section{REFERENCES}

[1] Bertrand A, Aggoune R, Maréchal F. (2017). In building waste water heat recovery: An urban-scale method for the characterization of water streams and the assessment of energy savings and costs. Appl. Energy 192: 110-125.

[2] Matsumoto K, Doumpos M, Andriosopoulos K. (2018). Historical energy security performance in EU countries. Renew. Sustain. Energy Rev. 82: 1737-1748.

[3] Chalvatzis KJ, Ioannidis A. (2017). Energy supply security in the EU: Benchmarking diversity and dependence of primary energy. Appl. Energy 207: 465476.

[4] Dieckhöner C, Lochner S, Lindenberger D. (2013). European natural gas infrastructure: the impact of market developments on gas flows and physical market integration. Appl. Energy 102: 994-1003.
[5] Nagy K, Körmendi K. (2012). Use of renewable energy sources in light of the "New Energy Strategy for Europe 2011-2020’. Appl. Energy 96: 393-399.

[6] Eurostat. http://ec.europa.eu/eurostat, accessed on 31/03/2018.

[7] Bianco V, Scarpa F, Tagliafico LA. (2015). Long term outlook of primary energy consumption of the Italian thermoelectric sector: impact of fuel and carbon prices. Energy 87: 153-164.

[8] BPIE, Buildings Performance Institute Europe. Europe's buildings under the microscope, 2011.

[9] Asare-Bediako B, Klinga WL, Ribeiro PF. (2014). Future residential load profiles: Scenario-based analysis of high penetration of heavy loads and distributed generation. Energy Build 74: 228-238.

[10] Yang L, Yan H, Lam JC. (2014). Thermal comfort and building energy consumption implications - a review. Appl. Energy 115: 164-173.

[11] Scarpa F, Bianco V. (2017). Assessing the quality of natural gas consumption forecasting: An application to the Italian residential sector. Energies 10(11): 1879.

[12] Bianco V, Scarpa F, Tagliafico LA. (2014). Analysis and future outlook of natural gas consumption in the Italian residential sector. Energy Convers. Manage 87: 754-764.

[13] Shi Y, Segerberg H. (2014). Integration of 100\% microdistributed energy resources in the low voltage distribution network: A Danish case study. Appl. Therm. Eng. 71: 797-808.

[14] Skema GR, Marcinauskas K, Korsakiene I. (2016). A review on heat pumps implementation in Lithuania in compliance with the national energy strategy and EU policy. Renew. Sustain. Energy Rev. 53: 841-858.

[15] Gupta R, Irving R. (2014). Possible effects of future domestic heat pump installations on the UK energy supply. Energy Build. 84: 94-110.

[16] Seck GS, Guerassimoff G, Maïzi N. (2015). Heat recovery using heat pumps in non energy intensive industry: Are energy saving certificates a solution for the food and drink industry in France? Appl Energy 156: 374-389.

[17] Caldera M, Ungaro P, Cammarata G, Puglisi G. (2018). Survey-based analysis of the electrical energy demand in Italian households. Mathematical Modelling of Engineering Problems 5(3): 217-224. https://doi.org/10.18280/mmep.050313

[18] Bianco V, Scarpa F. (2018). Impact of the phase out of French nuclear reactors on the Italian power sector. Energy 150: 722-734.

[19] ENEA AAVV. (2017). Analisi trimestrale del Sistema energetico Italiano - I trimestre 2017. p. 22.

[20] SNAM. Snam Rete Gas. http://www.snam.it/it/chisiamo/struttura-societaria/snam-rete-gas/, accessed on 31/03/2018.

[21] Eurometeo.http://www.eurometeo.com/italian/home, accessed on $31 / 03 / 2018$.

[22] AbdAlla S, Bianco V, Scarpa F, Tagliafico L. (2018). Impact of the utilization of heat pumps for buildings heating in the Italian power market. Conference EEM 2018 . 


\section{NOMENCLATURE}

$\mathrm{E}$

$\mathrm{E}_{\mathrm{b}}$

$\mathrm{E}_{\mathrm{CO} 2 \text {,Tot }}$

$\mathrm{E}_{\mathrm{CO} 2, \mathrm{G}}$

$\mathrm{E}_{\mathrm{CO} 2, \mathrm{PM}}$

$E_{h}$

EL

$\mathrm{EL}_{\mathrm{n}}$

$\mathrm{HHV}, \mathrm{H}_{\mathrm{H}}$

HP hour, J ${ }^{10} \mathrm{C}^{-1}$ daily gross energy consumption of natural gas, J

base load energy, J

total carbon emissions, $\mathrm{kg}$

carbon emission level for heating by means of the traditional natural gasbased heating systems, $\mathrm{kg}$

carbon emissions from the power market

(after switching), $\mathrm{kg}$

daily net amount of natural gas required for winter heating, $\mathrm{J}$

heat pump electrical energy needs, $\mathbf{J}$ new value of electricity demand per

natural gas High Heating Value, J. kg-

heat-pump

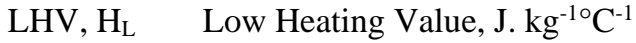

$\mathrm{Q}_{\mathrm{h}}$ net thermal energy needs to heat the building [J]

$\begin{array}{ll}\mathrm{T}_{\mathrm{amb}} & \text { ambient (internal) temperature, }{ }^{\circ} \mathrm{C} \\ \mathrm{T}_{\text {cond }} & \text { heat-pump condenser temperature, }{ }^{\circ} \mathrm{C}\end{array}$

$\mathrm{T}_{\mathrm{ev}} \quad$ heat-pump evaporator temperature, ${ }^{\circ} \mathrm{C}$

$\mathrm{T}_{\text {ext }} \quad$ external (environmental)

temperature, ${ }^{\circ} \mathrm{C}$

$\mathrm{T}_{\text {ext,h }} \quad$ external environmental temperature for the hour " $h$ ", ${ }^{\circ} \mathrm{C}$

SR switching rate of heating systems from gas to electricity, \%

UE unserved energy, J

\section{Greek symbols}

$\eta_{\mathrm{ex}} \quad$ "second law" efficiency

